University of Nebraska - Lincoln

DigitalCommons@University of Nebraska - Lincoln

$5-31-2000$

\title{
Airflow Characteristics of Commonly Used Temperature Radiation Shields*
}

X. Lin

University of Nebraska - Lincoln

Kenneth G. Hubbard

University of Nebraska-Lincoln, khubbard1@unl.edu

George E. Meyer

University of Nebraska - Lincoln

Follow this and additional works at: https://digitalcommons.unl.edu/natrespapers

Part of the Natural Resources and Conservation Commons, Natural Resources Management and Policy Commons, and the Other Environmental Sciences Commons

Lin, X.; Hubbard, Kenneth G.; and Meyer, George E., "Airflow Characteristics of Commonly Used Temperature Radiation Shields*" (2000). Papers in Natural Resources. 1099.

https://digitalcommons.unl.edu/natrespapers/1099

This Article is brought to you for free and open access by the Natural Resources, School of at DigitalCommons@University of Nebraska - Lincoln. It has been accepted for inclusion in Papers in Natural Resources by an authorized administrator of DigitalCommons@University of Nebraska - Lincoln. 


\title{
Airflow Characteristics of Commonly Used Temperature Radiation Shields*
}

\author{
X. Lin and Kenneth G. Hubbard \\ School of Natural Resource Sciences, University of Nebraska, Lincoln, Nebraska \\ George E. Meyer \\ Biological System Engineering Department, University of Nebraska, Lincoln, Nebraska
}

(Manuscript received 21 January 2000, in final form 31 May 2000)

\begin{abstract}
The air temperature radiation shield is a key component in air temperature measurement in weather station networks; however, it is widely recognized that significant errors in the measured air temperature exist due to insufficient airflow past the air temperature sensor housed inside the shield. During the last several decades, the U.S. National Weather Service has employed a number of different shields in air temperature measurements. This paper focuses on the airflow characteristics inside air temperature shields including the Maximum-Minimum Temperature System (MMTS), the Gill shields, and the Cotton Region Shelter (CRS).

Average airspeed profiles and airflow efficiency inside the shields are investigated in this study under both windtable and field conditions using an omnidirectional hot-wire sensor. Results from the windtable measurements indicate that the average airspeeds inside the shields oscillated along the center line of the Gill and MMTS shields as the "windtable air" speed was changed from 1.03 to $2.62 \mathrm{~m} \mathrm{~s}^{-1}$; the MMTS airflow efficiency demonstrated a nearly constant value, but the Gill's airflow efficiency increased. A linear transfer equation between the airspeed measured at the normal operating position for the temperature sensor inside the shield and the ambient wind speed was found under field conditions for all three nonaspirated air temperature radiation shields (CRS, Gill, and MMTS). Results indicate that the naturally ventilated temperature radiation shields are unable to provide sufficient ventilation when the ambient wind speed is less than $5 \mathrm{~m} \mathrm{~s}^{-1}$ at the radiation shield height.
\end{abstract}

\section{Introduction}

Air temperature is a measure of air thermal energy. Maintaining thermal equilibrium between the sensor and the air is critical when the air temperature is measured by any direct contact temperature sensor. Physically, the following equation can be used to describe the energetics of a thermal temperature sensor measurement:

$$
\begin{aligned}
m c \frac{d T_{\mathrm{sen}}}{d t}= & \alpha_{\mathrm{SR}} \mathrm{SR}+\varepsilon_{\mathrm{IR}} \mathrm{IR}-\varepsilon_{\mathrm{IR}} A \sigma T_{\mathrm{sen}}^{4} \\
& -A H\left(T_{\mathrm{sen}}-T_{\mathrm{air}}\right)+A_{\mathrm{wi}} k_{\mathrm{wi}} \frac{d T_{\mathrm{wi}}}{d l_{\mathrm{wi}}}
\end{aligned}
$$

where $A=$ sensor surface area $\left(\mathrm{m}^{2}\right), A_{\mathrm{wi}}=$ cross-sec-

\footnotetext{
* This paper has been approved as Journal Number 13007 of the Nebraska Agricultural Experiment Station.
}

Corresponding author address: Dr. Kenneth G. Hubbard, School of Natural Resource Sciences, University of Nebraska, L. W. Chase Hall, P.O. Box 830728, Lincoln, NE 68583-0728.

E-mail: khubbard@unlnotes.unl.edu tional area of sensor lead wires $\left(\mathrm{m}^{2}\right), H=$ convective heat transfer coefficient $\left(\mathrm{W} \mathrm{m} \mathrm{m}^{-2} \mathrm{~K}^{-1}\right), \mathrm{IR}=$ infrared radiant flux on the sensor $(\mathrm{W}), \mathrm{SR}=$ solar radiant flux on the sensor (W), $T_{\text {air }}=$ air temperature $(\mathrm{K}), T_{\text {sen }}=$ the sensor's temperature $(\mathrm{K}), T_{\mathrm{wi}}=$ temperature of the sensor lead wire (K), $c=$ specific heat capacity of the sensor $\left(\mathrm{J} \mathrm{kg}^{-1} \mathrm{~K}^{-1}\right), k_{\mathrm{wi}}=$ thermal conductivity of the lead wires $\left(\mathrm{W} \mathrm{m}^{-1} \mathrm{~K}^{-1}\right), l_{\mathrm{wi}}=$ length of the lead wires (m), $m=$ mass of the temperature sensor $(\mathrm{kg}), t=$ time (s), $\alpha_{\mathrm{SR}}=$ solar absorptivity of the sensor surface (nondimensional), $\varepsilon_{\mathrm{IR}}=$ infrared emissivity of the sensor surface (nondimensional), and $\sigma=$ Stefan-Boltzmann constant $\left(5.67 \times 10^{-8} \mathrm{~W} \mathrm{~m}^{-2} \mathrm{~K}^{-4}\right)$. The term on the left-hand side of Eq. (1) is the net change in internal energy of the temperature sensor. The terms on the righthand side of Eq. (1) from left to right are the absorbed solar radiation, absorbed infrared radiation, infrared radiation emission, convective heat transfer, and conductive heat transfer along the sensor wire. A good air temperature radiation shield should remove solar radiation $(\mathrm{SR} \rightarrow 0$ ), equilibrate absorbed infrared radiation $\left(\mathrm{IR}=A \sigma T_{\mathrm{sen}}^{4}\right)$ with emitted infrared radiation, and minimize the blockage of airflow to the temperature sensor. A large convection heat coefficient in the vicinity of the 


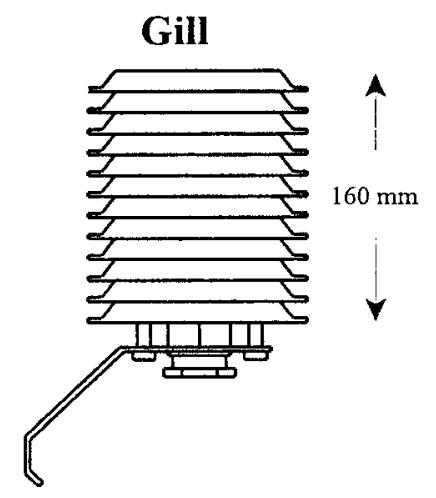

\section{MMTS}

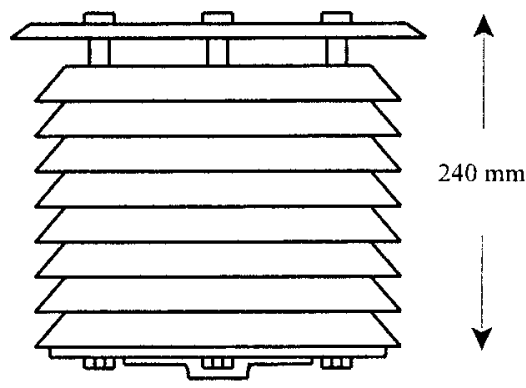

CRS

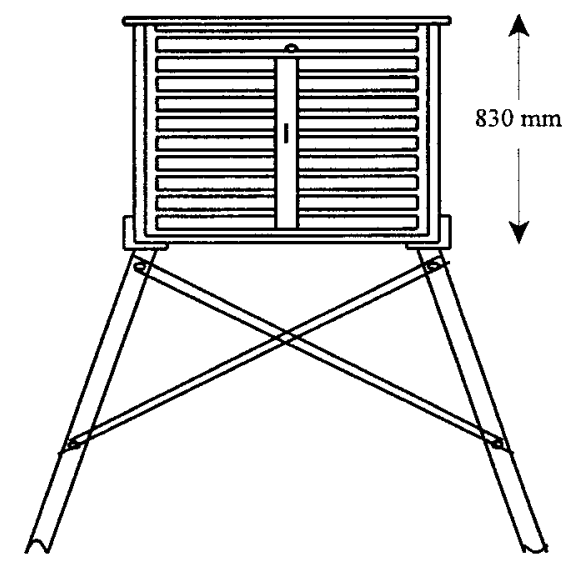

FIG. 1. Air temperature radiation shields commonly used in the United States: the Gill shield, the MMTS shield, and the Cotton Region Shelter (CRS).

sensor will lead to thermal equilibrium between the sensor and the passing air.

Currently, there are three types of nonaspirated air temperature radiation shields commonly used for air temperature observations in weather station networks in the United States. These shields are the Cotton Region Shelter (CRS), the Maximum-Minimum Temperature System (MMTS), and the Gill shields (Fig. 1). The geometrical design of the shield influences the airflow characteristics inside a shield. Thus, it is necessary to in- vestigate the airflow and to characterize its effects on the errors in the air temperature measurements.

Previous studies of airflow dynamics of radiation shields have been conducted by wind tunnel experiments (Brock et al. 1995) and numerical simulations (Richardson 1995a,b). Air temperature errors due to radiative heating inside the shields were inversely proportional to the airflow speed through the shield (Richardson 1995b). When the airspeed was low $\left(<2 \mathrm{~m} \mathrm{~s}^{-1}\right)$ and the insolation was high $\left(>700 \mathrm{~W} \mathrm{~m}^{-2}\right)$, the air temperature errors were quite large, $>2{ }^{\circ} \mathrm{C}$ (Brock et al. 1995). Richardson (1995a,b) simulated the airflow through shields using the general-purpose software package Fluent for modeling fluid flow, heat transfer, and chemical reaction. Richardson (1995a,b) investigated the airflow profile inside the Gill shield under both wind tunnel measurement and numerical simulation. The radiation shield airflow efficiency concept was introduced by Brock et al. (1995) and defined as the ratio of the average airspeed inside the shield to the average airspeed outside the shield (Brock et al. 1995; Richardson 1995a,b) in their studies for the Gill shield. A flow efficiency of 1.0 indicates the average flow on the centerline of the shield is the same as the ambient flow, while a flow efficiency of 0.0 means there is no flow through the shield. There is little information available on temperature response for the CRS and MMTS shields. Furthermore, the research mentioned above only investigated the airflow profile inside shields for low flow conditions, $1 \mathrm{~m} \mathrm{~s}^{-1}$.

The present study investigated the flow characteristics inside the Gill, MMTS, and CRS shields for a range of airspeeds. To conduct this research a windtable was constructed for use with the smaller radiation shields (Gill and MMTS). The airflow characteristics inside the Gill, MMTS, and CRS shields were also investigated in the field under natural ventilation. The specific objective of this study was to experimentally determine the airflow characteristics inside the three commonly used radiation shields. To accomplish this objective, the following aspects were investigated.

1) Airflow profiles and efficiency profiles inside the Gill and MMTS shields under different ambient airspeeds $\left(1.03,1.82\right.$, and $\left.2.62 \mathrm{~m} \mathrm{~s}^{-1}\right)$ from windtable experiments.

2) Airspeed and airflow efficiency inside the Gill, MMTS, and CRS shields from field experiments.

3) Transfer equations to relate airspeed inside the shields to ambient wind speed.

\section{Materials and methods}

\section{a. Windtable design for the MMTS and Gill shields}

Airflow through the shields (Gill and MMTS) can be controlled by a windtable in a laboratory (Fig. 2). The windtable is supported by three steel legs (A) $460 \mathrm{~mm}$ in height and features an aluminum plate disk (B) 103 


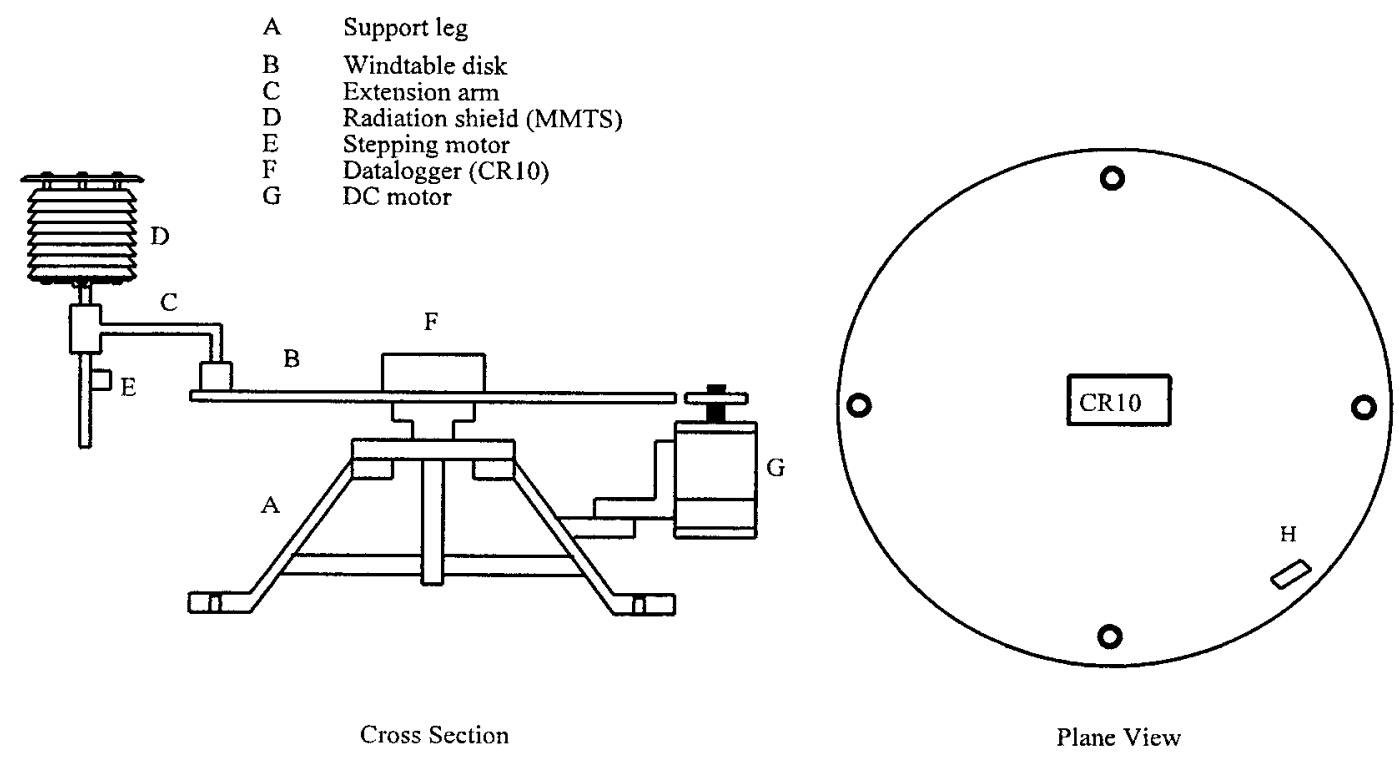

FIG. 2. Details of airflow windtable.

mm in diameter. A radiation shield [e.g., MMTS (D)] is mounted on the windtable by an extension arm $(C)$. A DC motor $(\mathrm{G})$ is used to rotate the windtable and is connected by a rubber wheel located on the armature of the DC motor. Each revolution of the windtable is sensed by two infrared light emitting diode (LED) sensors $(\mathrm{H})$. An infrared transmitter below the windtable emits infrared toward the rotating table where an infrared receiver produces a pulse with each revolution. The pulses from the infrared receiver were counted and recorded with a CR-10 datalogger (F) (Campbell Scientific Inc.). The speed of air passing through the shield $(V)$ or "windtable air" speed was calculated as

$$
V=\frac{\pi D N}{\Delta t}
$$

where $D$ is the distance from the center of the windtable to the center of the shield $(1.84 \mathrm{~m})$ and $\Delta t$ is the interval of time (s) during which $N$ counts were recorded.

An omnidirectional airspeed transducer (Model 8475, TSI Inc., 1995) was selected to measure the airspeed along the vertical axis inside the shield because it has a small probe tip with a spherical shape and the measurements are independent of the orientation of the sensor (omnidirectional). The sensing head of the transducer is a 2-mm-diameter sphere and the measurement range given by TSI is from 0 to $2.5 \mathrm{~m} \mathrm{~s}^{-1}$. The TSI transducer was moved up and down inside the shield by a stepping motor (E) and coupled brass rack and pinion. The TSI air velocity transducer was recalibrated by the manufacturer prior to the experiment. The adjustable time constant for the TSI transducer was set to $10 \mathrm{~s}$, and a 20 -s sample rate was selected. All data were obtained from averaging nine readings (i.e., 3-min time averages). All data were taken without any external air- flow sources (e.g., air conditioning outlet) during the measurements.

\section{b. Experiments on validation of the windtable}

Since the rotation of the windtable causes some air movement, it cannot be considered as an absolute method to calibrate an anemometer. However, very good results can be achieved when the anemometers are compared with certified anemometers of the same design (Fritschen and Gay 1979). Therefore, for the current application, two important questions should be posed before the windtable was applied to our study. (a) Does the windtable speed [Eq. (2)] directly represent the TSI transducer readings? (b) Does the vertical airspeed profile above the windtable remain constant within the height span for which the MMTS and Gill shields were mounted?

To answer the first question, the TSI transducer was mounted on the extension arm of the windtable at 835 $\mathrm{mm}$ above the ground surface, approximating the average height of the MMTS or Gill shields when mounted on the windtable. Both the rotation rates of the windtable and windtable airspeed indicated from the TSI transducer were recorded by the datalogger. To obtain the vertical profiles of airspeed above the windtable, the TSI transducer was mounted on one side of the windtable and the Gill or MMTS shield was mounted on the other. The TSI transducer height was raised from 650 to $900 \mathrm{~mm}$ above the ground surface, which covered the entire range of TSI transducer positions when it was used for measuring airspeeds inside the Gill and MMTS shields on the windtable. The windtable was operated at three different windtable airspeeds $(1.09,1.92$, and $2.49 \mathrm{~m} \mathrm{~s}^{-1}$ ) during the vertical profiling of airspeed above the windtable. 


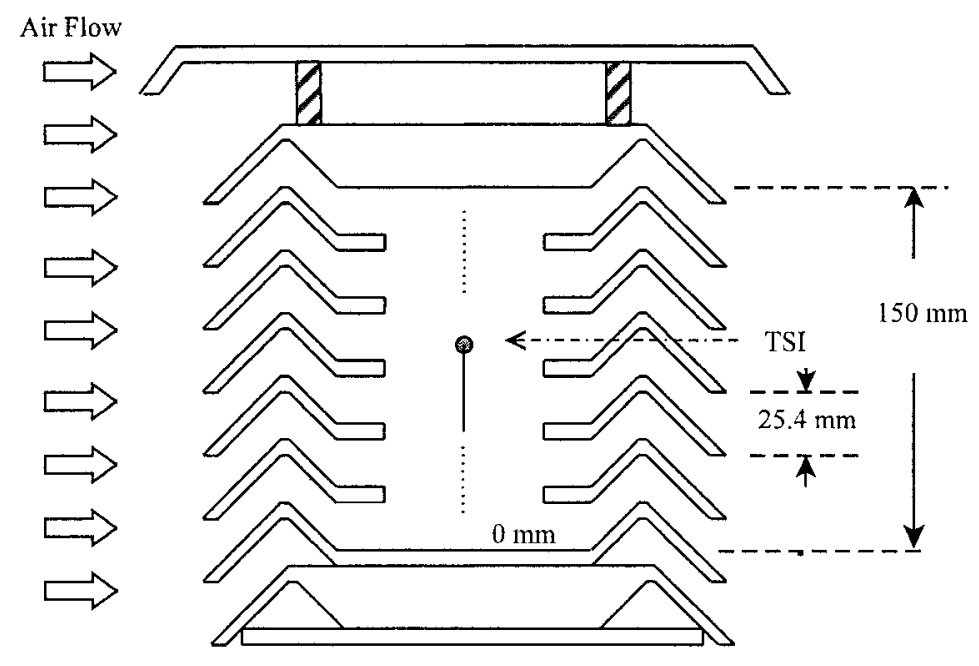

Cross-section of the MMTS

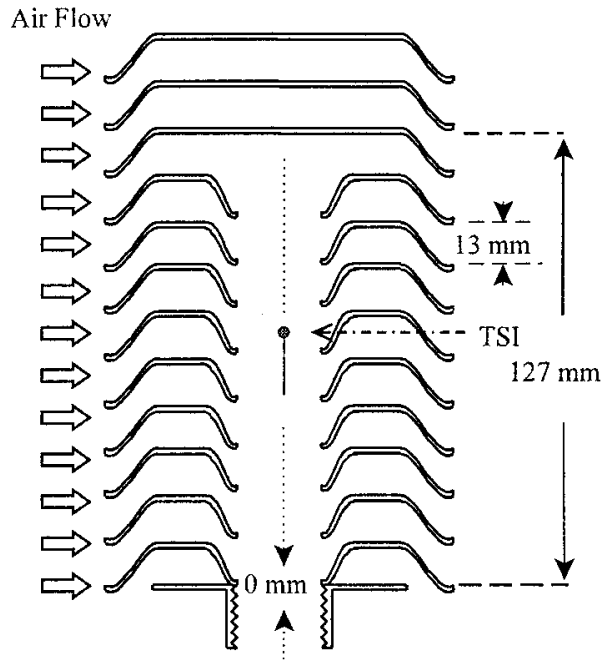

Cross-section of the Gill

FIG. 3. Measurement locations of ominidirectional airspeed transducer TSI Model 8475 inside the MMTS and Gill shields. The stepping motor with the rack and pinion moved the TSI transducer a distance of $5 \mathrm{~mm}$ along the vertical axis of the shield each step from 0 to 145 $\mathrm{mm}$ and from 0 to $125 \mathrm{~mm}$ for the MMTS and Gill shields, respectively.

\section{c. Measurements inside the MMTS and Gill shields on the windtable}

Figure 3 illustrates the TSI transducer locations where airspeed was measured inside the MMTS and Gill shields. The MMTS and Gill shields have an inner cylindrical opening with 150 and $127 \mathrm{~mm}$ in height, respectively. The MMTS shield has a closed bottom so that it was necessary to bore a hole $30 \mathrm{~mm}$ in diameter in the center of the base to insert the TSI transducer. The rack and pinion motor moved the TSI transducer a distance of $5 \mathrm{~mm}$ along the vertical axis of the shield each $30 \mathrm{~min}$. The $20-\mathrm{min}$ average at each height was formed after dropping the first and last $5 \mathrm{~min}$ of data so that the transient errors in airspeed measurement, caused by the windtable settling time, the time constant of the TSI transducer, and starting speed by the MetOne anemometer, were eliminated.

\section{d. Field measurements inside the Gill, MMTS, and CRS shields}

A field experiment was conducted on the roof of the Biological Engineering Laboratory located on the East Campus of the University of Nebraska Lincoln. The CRS is too large to mount on the windtable but was included in the field experiment. The airspeed inside the shield at the position normally occupied by the temperature sensor was measured with the TSI transducer. The ambient wind speed was measured by a Met-One anemometer (Met One Instruments) at a height of 1.5 $\mathrm{m}$ and a separation distance of $5 \mathrm{~m}$ from the radiation shield to the Met-One anemometer. The time constant of the TSI transducer was set to $1 \mathrm{~s}$. Because of design difference the TSI transducer and the Met-One anemometer do not sample the same volume of air. Based on trial and error we found a 2-s sampling rate for the TSI air velocity transducer and $5 \mathrm{~s}$ for Met-One anemometer gave a reasonable comparison. Since the MetOne anemometer provides average wind speed measurement within the sampling interval, 1-min averages for both the TSI transducer and Met-One anemometer were taken as final output data.

\section{Results}

\section{a. Validation of windtable airspeed and vertical} profiles

The airspeed calculated by Eq. (2) was compared to the airspeed as measured with the TSI transducer (Fig. 4a). Each point for the TSI measurements (open square symbols in Fig. 4a) represents the half-hour average (obtained from averaging 90 sample readings). The result was less than $0.1 \mathrm{~m} \mathrm{~s}^{-1}$ difference in the range from about 0.5 to $1.5 \mathrm{~m} \mathrm{~s}^{-1}$ and less than a $0.2 \mathrm{~m} \mathrm{~s}^{-1}$ difference in the range from 1.5 to $2.5 \mathrm{~m} \mathrm{~s}^{-1}$. Therefore, Eq. (2) was used for this study.

The airspeed variations associated with changes in TSI transducer height are shown in Fig. 4b. The vertical profiles of the TSI transducer measurements at the 1.09 $\mathrm{m} \mathrm{s}^{-1}, 1.92 \mathrm{~m} \mathrm{~s}^{-1}$, and $2.49 \mathrm{~m} \mathrm{~s}^{-1}$ windtable airspeeds were within $0.1 \mathrm{~m} \mathrm{~s}^{-1}$ at the same windtable airspeed (Fig. 4b). Airspeeds measured by the TSI transducer were nearly the same for any height $(650-900 \mathrm{~mm})$ whether the MMTS or Gill shield was mounted on the windtable. When mounted with the base at $650 \mathrm{~mm}$, both the MMTS and the Gill fit in this $650-900-\mathrm{mm}$ 
a. Comparison between the TSI measurements and calculations

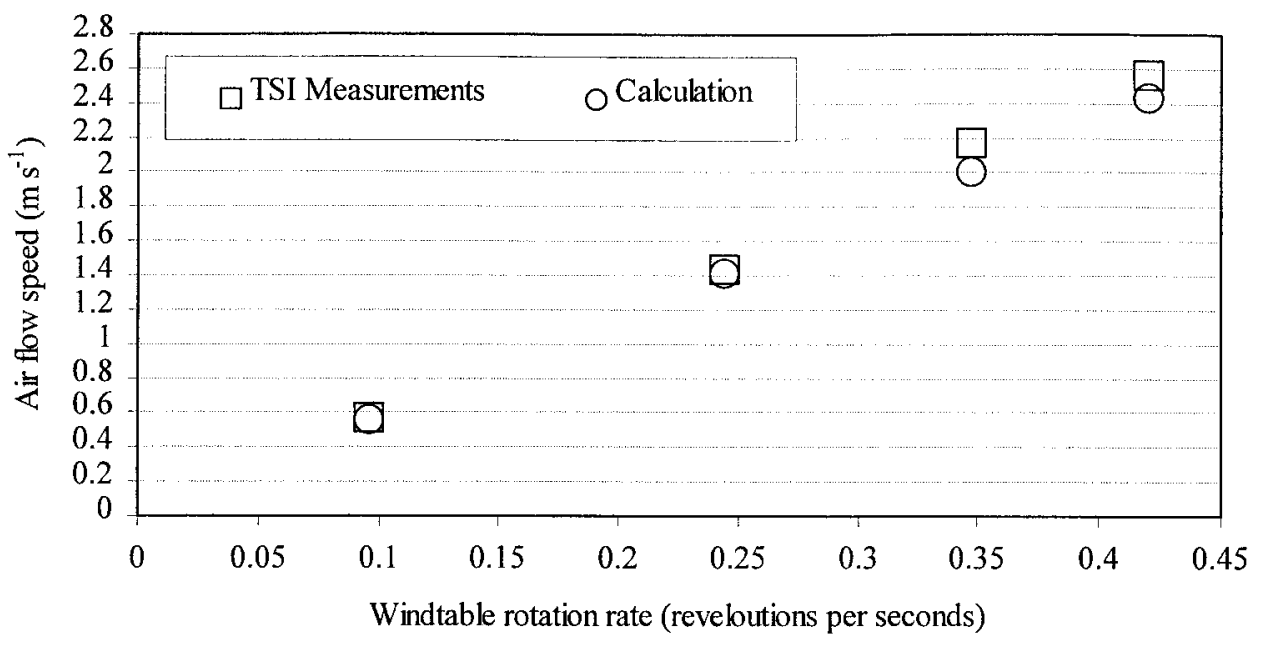

b. Nominal air speed or 'windtable air' speed pofiles

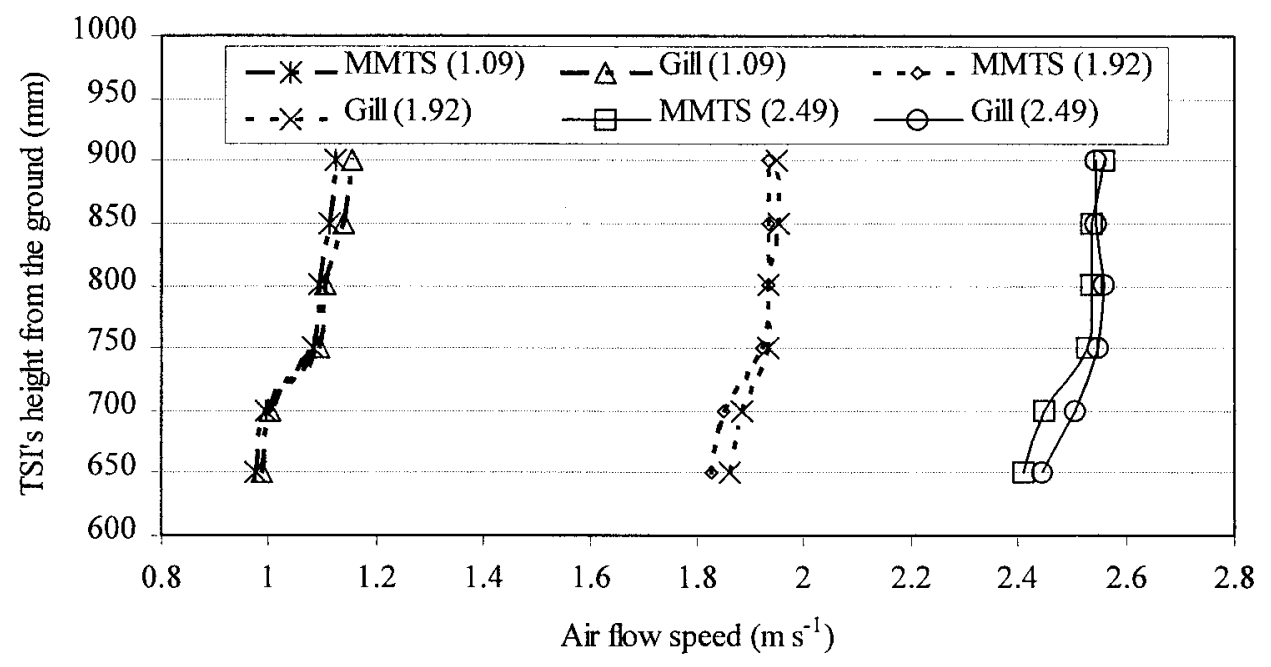

FIG. 4. Validation of windtable airspeed and vertical profiles.

span. Thus the "ambient" profile simulated by the windtable was nearly constant and represented a reasonable constant airflow field in which to study the inner airflow characteristics of the MMTS and Gill shields.

\section{b. Airflow inside Gill and MMTS shields on the windtable}

\section{1) AirspeEd AND AIRFLOW EFFICIENCY PROFILES}

There are six gaps (24.5 $\mathrm{mm}$ in thickness) between two continuous plates through which air flows to the inner space in the MMTS shield (Fig. 3). The airspeed profiles and airflow efficiency for windtable airspeeds of 1.03 , 1.82, and $2.62 \mathrm{~m} \mathrm{~s}^{-1}$ inside the MMTS shield on the windtable indicated five local maxima corresponded to the five plate positions in the inner open space of the
MMTS shield (Fig. 5a). Six local minima were clearly visible at the middle position of six gaps. The maximum airspeed was located at the first gap from the bottom and the second maximum airspeed was at the sixth gap, just below the top of the inner open space. As the windtable airspeed increased from 1.03 to $2.62 \mathrm{~m} \mathrm{~s}^{-1}$, a third maximum, in the inner open space of the middle plate position, was accentuated. The remaining gaps gave progressively smaller maximum airspeeds, and the second gap from the bottom did not indicate a clear maximum but only a change in slope. Airflow efficiency profiles had the same shapes as the airspeed profiles inside the MMTS (Fig. 5b). However, when the windtable airspeed increased, the airflow efficiency inside the MMTS shield tended to be constant at about 0.3 in average.

Air passing to the inner open space in the Gill shield 

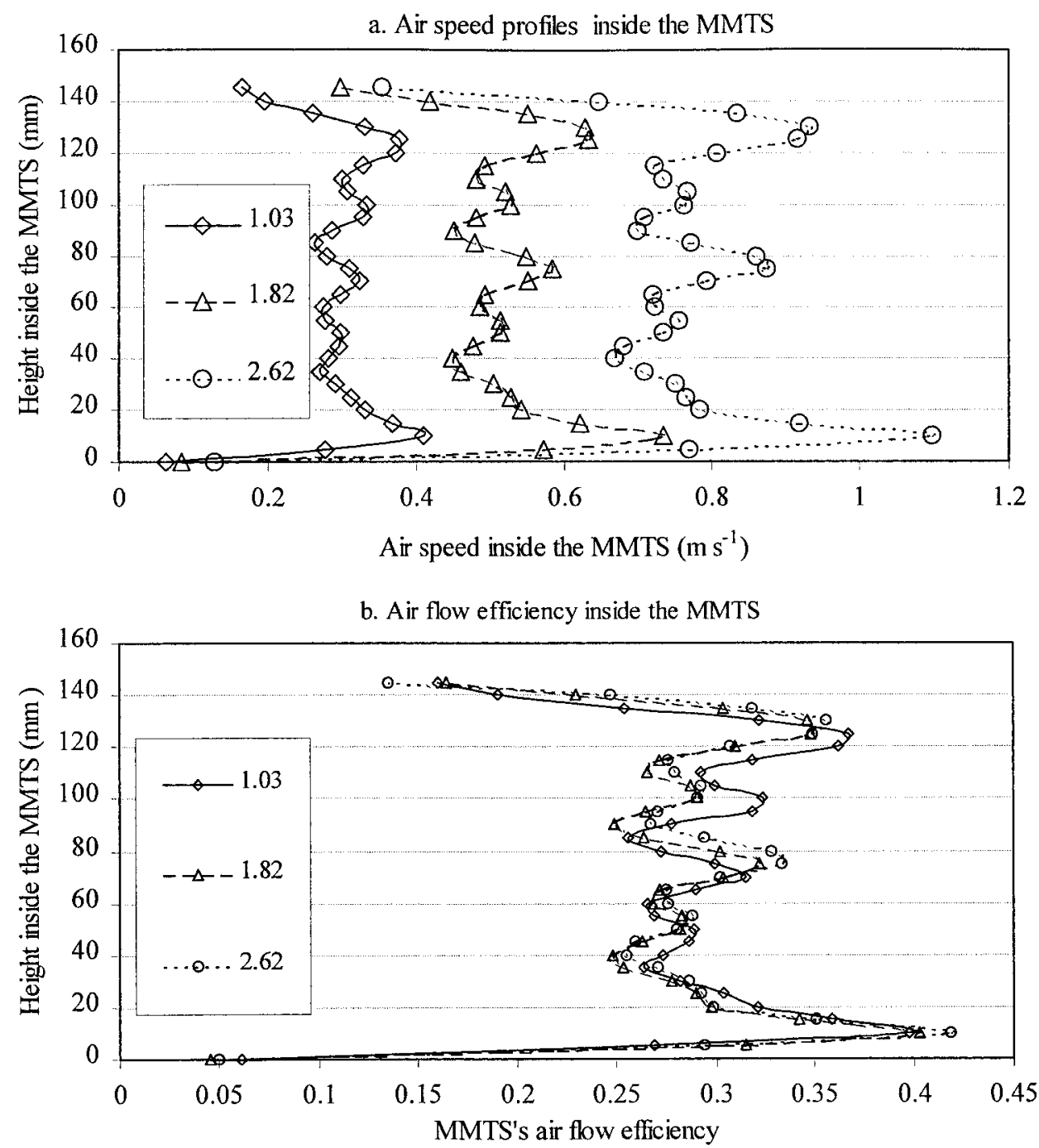

FIG. 5. Airspeed profiles and air efficiency inside the MMTS shield under the windtable airspeed with $1.03,1.82$, and $2.62 \mathrm{~m} \mathrm{~s}^{-1}$.

must pass through any of the nine gaps $(13 \mathrm{~mm}$ in thickness) located between plates (Fig. 3). The airspeed profiles and airflow efficiency for windtable airspeeds of $1.03,1.82$, and $2.62 \mathrm{~m} \mathrm{~s}^{-1}$ inside the Gill shield on the windtable indicated that there was 1) a "bulge" point in the lower part of the inner open space near 10$\mathrm{mm}$ height, 2) a local minimum at $12 \mathrm{~mm}$ below the top, and 3) a "jet" at the highest part of the inner open space inside the Gill (Fig. 6). When the windtable airspeed was $1.03 \mathrm{~m} \mathrm{~s}^{-1}$ the airspeed profile inside the Gill was virtually a vertical line from 20 to $100 \mathrm{~mm}$. A regular oscillating profile was seen to follow the Gill geometry with the local maxima near each plate position at the $1.82 \mathrm{~m} \mathrm{~s}^{-1}$ windtable airspeed. The local minima were located at the middle of gaps from 19 to $55 \mathrm{~mm}$. However, when the windtable airspeed reached $2.62 \mathrm{~m}$ $\mathrm{s}^{-1}$, the oscillating variations following plate positions no longer were detected; instead two bulges in the pro- files were observed: a large curvature from a height of $10-70 \mathrm{~mm}$ with a minimum at about $40 \mathrm{~mm}$ and another significant curvature between 70 and $110 \mathrm{~mm}$ with a maximum at about $100 \mathrm{~mm}$. The airflow efficiency for the Gill shield had the same common features as the airspeed inside the Gill (Fig. 6b). However, the airflow efficiency profiles for 1.82 and $2.62 \mathrm{~m} \mathrm{~s}^{-1}$ windtable airspeed overlapped. Therefore, increasing the windtable airspeed did noticeably increase airflow efficiency at the lower airspeed up to $1.82 \mathrm{~m} \mathrm{~s}^{-1}$.

\section{2) Airflow At NORMAl OPERATING SENSOR POSITIONS}

The normal operating air temperature sensor height varies from about 100 to $105 \mathrm{~mm}$ inside the MMTS shield and from 70 to $75 \mathrm{~mm}$ inside the Gill shield. The airspeed inside the MMTS at the normal operating 
a. Air speed profiles inside the Gill

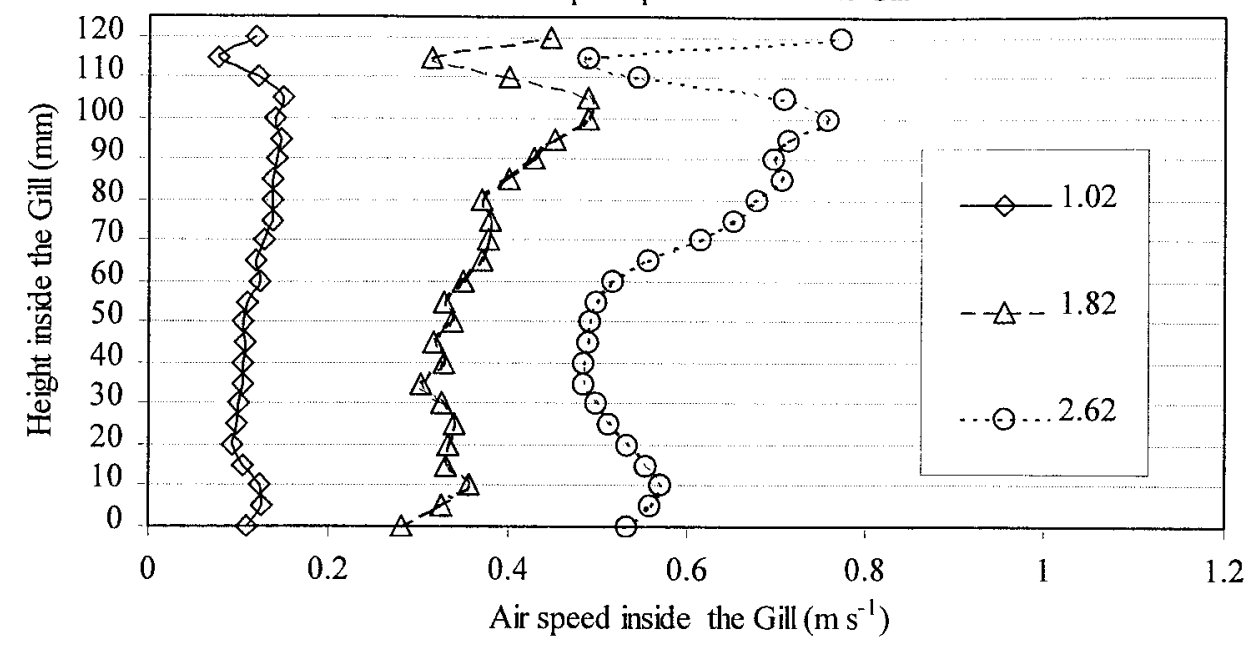

b. Air flow efficiency inside the Gill

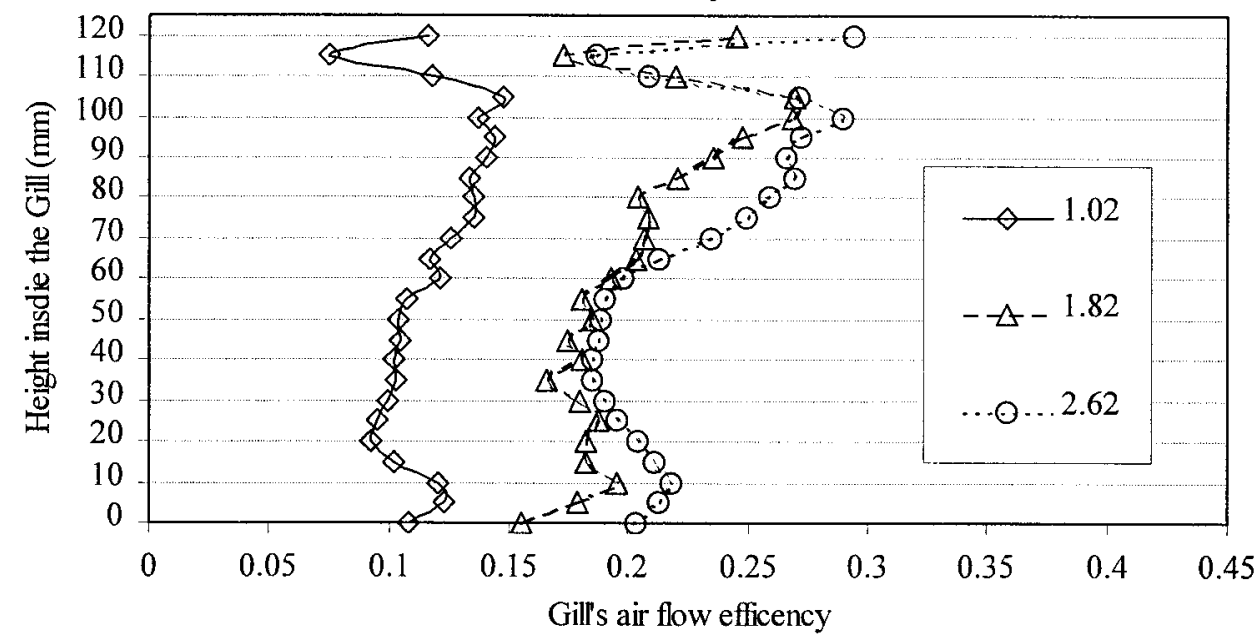

FIG. 6. Airspeed profiles and air efficiency inside the Gill shield under the windtable airspeed with 1.03, 1.82 , and $2.62 \mathrm{~m} \mathrm{~s}^{-1}$.

height for the temperature sensor increased with increasing windtable airspeed, and the relationship tended to be quite linear (Fig. 7a). The airflow efficiency of the MMTS tended to decrease with increasing windtable airspeed over the range from 0.5 to $2 \mathrm{~m} \mathrm{~s}^{-1}$ of the ambient wind speed, then seemed to be constant when the windtable airspeed was above $2 \mathrm{~m} \mathrm{~s}^{-1}$ (Fig. 7b).

The airspeed at the normal operating height for the air temperature sensor used in the Gill shield increased linearly with increasing windtable airspeed (Fig. 7c). Also, the airflow efficiency of the Gill tended to be nearly constant over the range of speeds in the study (Fig. 7d).

\section{c. Airflow inside the Gill, MMTS, and CRS during the field experiments}

The 1-min average airspeed inside the MMTS, Gill, and CRS shields under field conditions indicated a linear response to 1-min average ambient wind speed (solid lines in Fig. 8). The linear relationship of average airspeed inside the shields $\left(U_{\text {in }}\right)$ to the average ambient wind speed $\left(U_{\text {out }}\right)$ was represented by linear regression as follows:

MMTS:

$$
\begin{aligned}
U_{\text {in }} & =0.343 U_{\text {out }}-0.1359, \\
r^{2} & =0.95 \quad P<0.001, \\
U_{\text {in }} & =0.4964 U_{\text {out }}-0.2262, \\
r^{2} & =0.83 \quad P<0.001, \\
U_{\text {in }} & =0.2834 U_{\text {out }}-0.0038, \\
r^{2} & =0.84 \quad P<0.001,
\end{aligned}
$$$$
\text { Gill: } \quad U_{\text {in }}=0.4964 U_{\text {out }}-0.2262 \text {, }
$$$$
\text { CRS: } \quad U_{\text {in }}=0.2834 U_{\text {out }}-0.0038 \text {, }
$$

where $r^{2}$ is the coefficient of determination. The two dashed lines with open squares and open triangles represent the positive and negative standard deviation in 
a. Air speed inside the MMTS

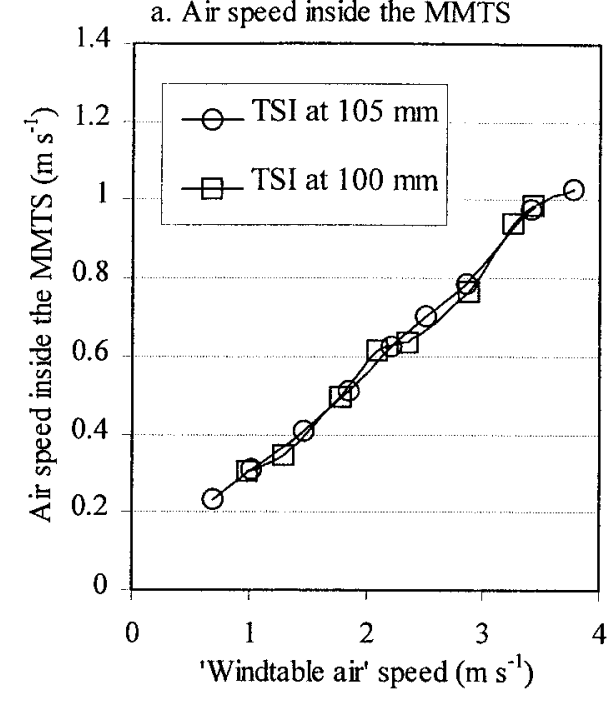

b. MMTS's air flow efficiency

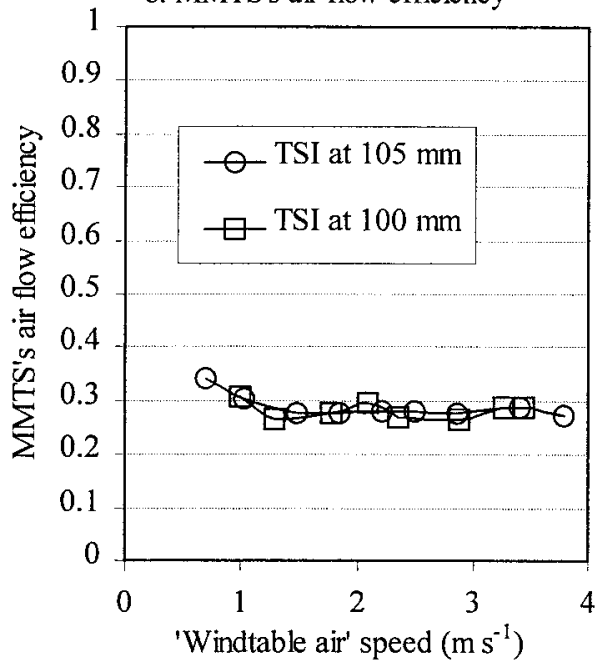

c. Air speed inside the Gill

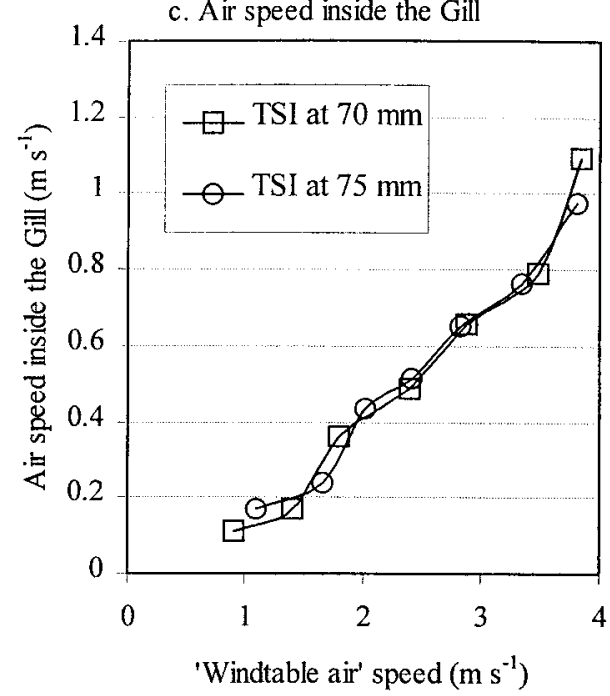

d. Gill's air flow efficiency

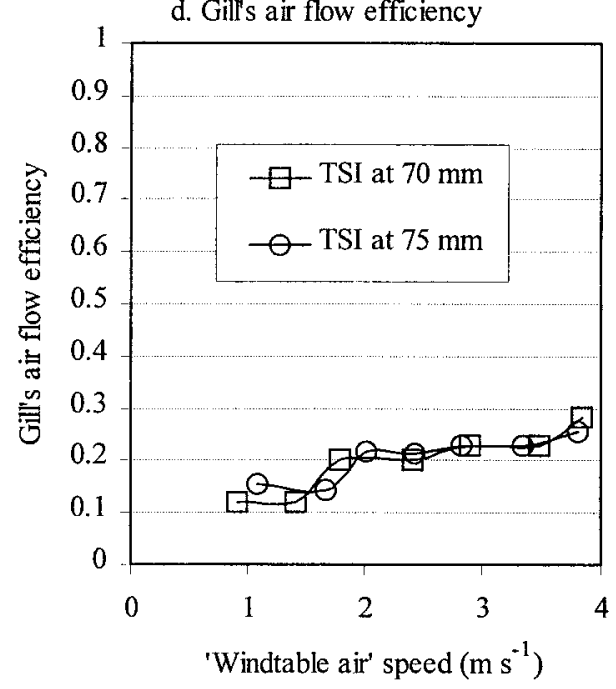

FIG. 7. Airspeeds and airflow efficiencies at the normal operating sensor height on the windtable.

the range $\pm 0.5 \mathrm{~m} \mathrm{~s}^{-1}$ of each corresponding data point. The airspeed inside the MMTS shield had the least variation about the linear relationship line. The airspeed inside the shield $\left(U_{\text {in }}\right)$ cannot take on negative values; therefore, negative values of $U_{\text {in }}$ in Eqs. (3)-(5) are set to zero. The value of $U_{\text {out }}$ when $U_{\text {in }}$ is zero indicates an airspeed threshold for the shield. This threshold is ordered Gill $>$ MMTS $>$ CRS. The airflow efficiency at the normal operating sensor height inside the CRS, Gill, and MMTS under the field condition is shown in Fig. 8 . The CRS has a nearly constant airflow efficiency from ambient wind speed of 2-6 $\mathrm{m} \mathrm{s}^{-1}$ (Fig. 8a). However, the efficiency of the CRS tends to increase for ambient wind speeds of $0.5-2 \mathrm{~m} \mathrm{~s}^{-1}$. Similarly, the MMTS shield's airflow efficiency remained relatively constant from ambient wind speeds of $0.5-6 \mathrm{~m} \mathrm{~s}^{-1}$ at the normal operating height for sensors but increased slightly in the
0.5-3 $\mathrm{m} \mathrm{s}^{-1}$ ambient wind speed (Fig. 8c). The airflow efficiency for the Gill shield was quite different from the MMTS and CRS shields (Fig. 8b), especially over the low wind speed range. The efficiency for the Gill tended to increase from ambient wind speeds of 0.5-2 $\mathrm{m} \mathrm{s}^{-1}$. Over all ranges of measurements, the MMTS' airflow efficiency was higher than that of the CRS shield. However, the Gill's airflow efficiency was the largest when the ambient wind speed was $2 \mathrm{~m} \mathrm{~s}^{-1}$ or greater.

\section{Discussion and conclusions}

Differences in airflow characteristics of the MMTS, Gill, and CRS shields can be traced to the airflow fields inside the shields. Flows involving complicated threedimensional geometries, especially with sharp-angle 

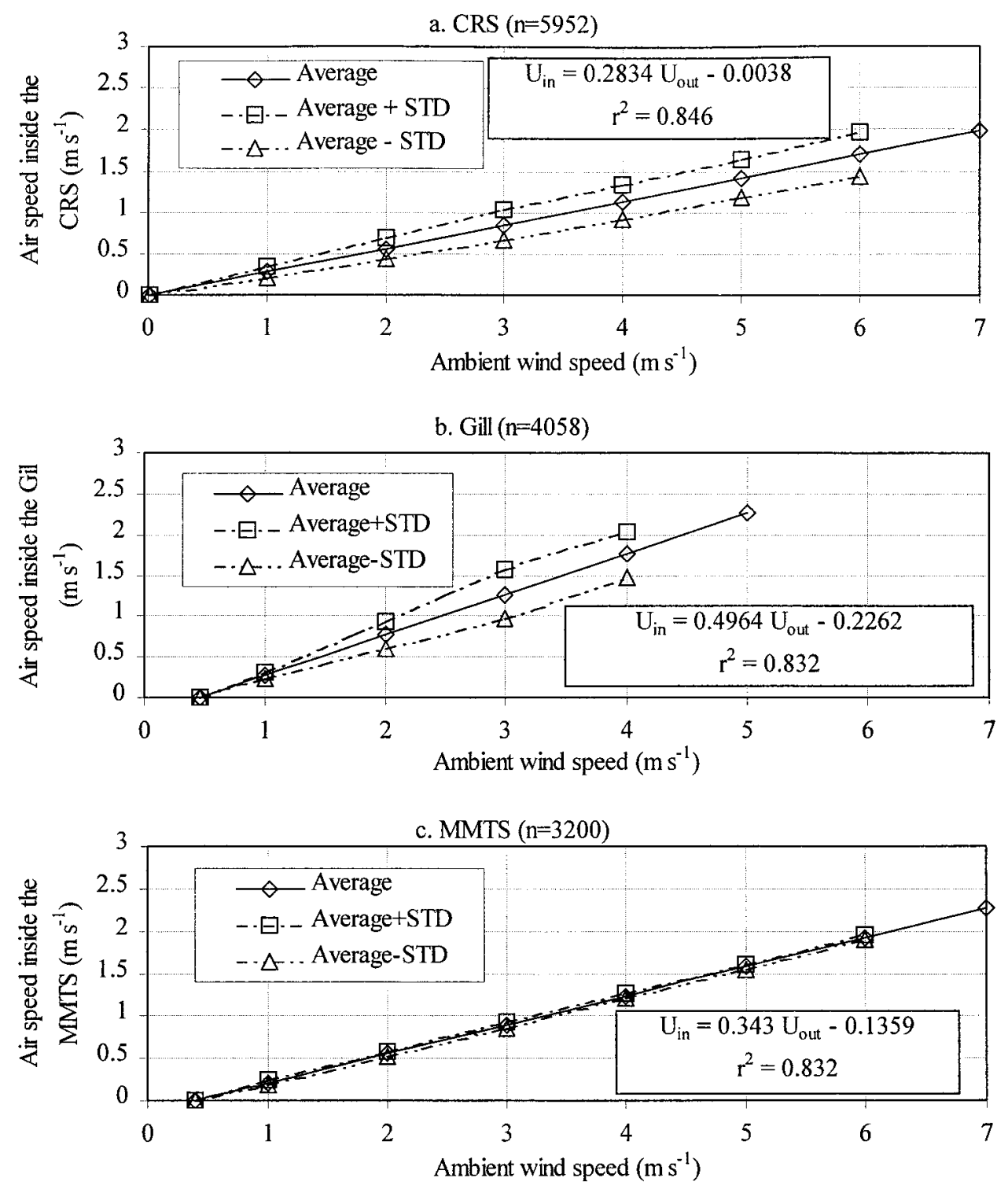

FIG. 8. Airspeed at the normal operating sensor height inside the shields under the field condition. The average lines represent the linear regression lines. The STD stands for the standard deviation for each point. The $\mathrm{n}$ represents data numbers.

turns, are rightly termed complex viscous flows and cannot be realistically treated by traditional boundarylayer methods. Such complex flows are studied either experimentally or, increasingly, by computer modeling (White 1991). Apparently the flow field for the shields is mainly determined by shield geometrical structure and surface characteristics. The oscillating nature of the airspeed profiles inside the MMTS on the windtable (Fig. 5a) appears to be related to the airflow streamlines. A wake zone or circulation cell and stronger streamlines may form inside the shields, depending on the shield geometry. The stronger streamlines may go out from the gaps between two plates into the centerline of the MMTS shield, forming greater airflow circulation across the middle position at gap levels in the shield's inner open space. A wake zone or circulation cell may be created between the two plates of the MMTS and Gill shields dominated by ambient airflow incident angle and speed. Since the measurements were only conducted on the centerline of the shield's inner space, these possibilities remain untested. The airflow "jet" was detected near the top and bottom plate inside both MMTS and Gill shields (Figs. 5 and 6). The phenomenon that keeps a jet attached to a solid boundary is termed the "Coanda effect" (Albright 1990). The Gill shield's velocity vectors from the numerical simulations (Richardson 1995a and 1995b) indicated three common characteristics of airflow inside the Gill shield, which were also identified 
TABLE 1. Summary of airflow efficiency of the radiation shields under the different ambient wind speed and windtable airspeed conditions. Each value for the field measurements was calculated from average of values within $\pm 0.03 \mathrm{~m} \mathrm{~s}^{-1}$ for each ambient wind speed.

\begin{tabular}{|c|c|c|c|c|c|c|c|c|c|}
\hline \multirow[b]{3}{*}{ Shields } & \multicolumn{9}{|c|}{ Airflow efficiency } \\
\hline & \multicolumn{5}{|c|}{ Field measurements* $\left(\mathrm{m} \mathrm{s}^{-1}\right)$} & \multicolumn{4}{|c|}{ Windtable measurements $\left(\mathrm{m} \mathrm{s}^{-1}\right)$} \\
\hline & 1.03 & 1.82 & 2.62 & 4.00 & 5.00 & 1.03 & 1.82 & 2.62 & $\mathrm{SH}^{* *}$ \\
\hline MMTS & 0.271 & 0.269 & 0.246 & 0.303 & 0.311 & 0.294 & 0.278 & 0.292 & 0.281 \\
\hline Gill & 0.183 & 0.365 & 0.437 & 0.431 & 0.417 & 0.122 & 0.202 & 0.22 & 0.202 \\
\hline CRS & 0.251 & 0.239 & 0.307 & 0.279 & 0.267 & NA & NA & NA & NA \\
\hline
\end{tabular}

* Measurements were taken at the normal operating sensor height under the field condition.

** The SH represents the average airflow efficiency value for the windtable airflow from about 0.5 to $3.5 \mathrm{~m} \mathrm{~s}^{-1}$ when the TSI transducer was placed at the normal operating temperature sensor height.

in this study: 1) a dead region or broad wake zone indicated in the top region of the inner open space, 2) enhanced circulation as ambient airspeed increased, and 3) a minimum in the lower profile and a maximum in the upper profile at $2.62 \mathrm{~m} \mathrm{~s}^{-1}$ windtable airspeed (Fig. $6 a)$. The changes in the vertical profile of horizontal wind make it critical to place all sensors at the same vertical position.

The difference in airflow efficiencies for the windtable and field studies is striking. It suggests that the character of the flow (turbulent intensity, steady, or unsteady) is an important factor in determining the relation between airspeed inside the shield and ambient airspeed. The relationship (Figs. 7a and 7c) from the windtable may be more applicable to steady flows such as cold air drainage or land and sea breezes. In other situations where the airflow is more unsteady, the relationship (Fig. 8) from the field studies may be more applicable. The findings for the Gill shield are partly confirmed by earlier findings reported by Brock et al. (1995) and Richardson (1995a). Brock et al. (1995) tested the Gill airflow profile for only $1 \mathrm{~m} \mathrm{~s}^{-1}$ ambient airspeed inside the wind tunnel. The airflow performance of the Gill shield from the numerical simulation (Richardson 1995a,b) yielded a similar wind speed profile inside the Gill shield to that observed during wind tunnel measurements. At a $1 \mathrm{~m} \mathrm{~s}^{-1}$ ambient airspeed, the Gill's airflow efficiency of 0.122 (for the windtable measurement) and 0.183 (for the field measurement) in this study are smaller than 0.3, which was obtained in the wind tunnel by Brock et al. (1995) or 0.37, which was simulated by Richardson (1995a,b). Differences between the studies include airflow controls and restrictions relative to the windtable and the lack of restrictions in the case of the field results. In any case, the airspeed sensor installation inside the shields may interfere with airflow during the measurements (Perry 1982; Bruun 1995). This interference may be more serious for the Gill shield than for the MMTS shield because of the larger open inner space inside the MMTS shield.

Each airflow efficiency for the field measurements was summarized in Table 1. In the natural environment where ambient wind speed ranged from about 0.5 to 1.5 $\mathrm{m} \mathrm{s}^{-1}$, the airflow efficiency ranked as follows:

$$
\text { MMTS }>\text { CRS }>\text { Gill. }
$$

When the ambient wind speed was greater than $1.5 \mathrm{~m}$ $\mathrm{s}^{-1}$, the airflow efficiency ranking was

$$
\text { Gill > MMTS > CRS. }
$$

In the windtable measurement, the average airflow efficiency of the entire inner open space inside the MMTS shield was larger than that inside the Gill shield for the windtable airspeeds of $1.03-2.62 \mathrm{~m} \mathrm{~s}^{-1}$. In addition, the airflow efficiency at the normal operating sensor height inside the MMTS was also greater than that inside the Gill.

The relationships between the airspeed inside shields and the ambient wind speed were linear for the MMTS, Gill, and CRS (Fig. 8). From this result, the airspeeds inside the MMTS, Gill, and CRS shields were generally less than about $2 \mathrm{~m} \mathrm{~s}^{-1}$ (the Gill shield) on average when the ambient wind speed was less than $5 \mathrm{~m} \mathrm{~s}^{-1}$. According to the World Meteorological Organization (WMO) recommendations on air temperature measurements, a desirable ventilation rate through the air temperature sensor inside the shield is $2.5 \mathrm{~m} \mathrm{~s}^{-1}$ or greater (WMO 1983). When the airspeed is less than $2 \mathrm{~m} \mathrm{~s}^{-1}$, a $\pm 0.2^{\circ} \mathrm{C}$ radiation error could be induced by the effect of certain solar and infrared loading on the surface of the air temperature sensor in the nonaspirated shields (Lin 1999). The average ambient wind speed does not often reach more than $5 \mathrm{~m} \mathrm{~s}^{-1}$ at Nebraska weather monitoring sites (Global Energy Concepts, Inc. 1999). Therefore, all three nonaspirated radiation shields (MMTS, Gill, and CRS) have a built-in error due to insufficient ventilation.

The airflow efficiency for the MMTS shield presented a nearly constant value of around 0.3 (Figs. $5 \mathrm{~b}$ and $8 \mathrm{c}$ ) under both field and windtable measurements. The airflow efficiency for the Gill shield in the windtable measurements was smaller than in the field measurements. However, the change in airflow efficiency (increasing ambient wind) of the Gill shield was the same for both field and windtable conditions. There were differences between airflow efficiencies in the windtable and field experiments, especially for the Gill shield (Table 1). Possible explanations for these differences may lie in 
the characteristics of the airflow. The airflow formed by the windtable may be laminar before it passes the shields, while the airflow in the field, in most cases, is turbulent near the ground surface. Because of design differences between the TSI transducer and the MetOne anemometer there may be fundamental differences in the way these sensors respond to these wind flow patterns. For example, it is well known that the cup anemometer can overspeed depending on the intensity of turbulence (Izumi and Barad 1970; Busch and Kristensen 1976; Wyngaard 1981). The TSI transducer is a thermal anemometer, which, in principle, is based on the measurement of the convective heat loss from a heated element to the surrounding air. The convective heat transfer is strongly related to the Nusselt number, $N_{u}$. However, $N_{u}$ has different values for different flows even at the same airspeed. The higher the intensity of the turbulence, the more effective the heat exchange is and the larger the convective coefficient. In addition, the thermal anemometer's accuracy is affected by measured airflow characteristics such as the pitch angle, yaw angle, and turbulent intensity (Scheiman et al. 1982; Bruun 1995). We speculate that the airflow efficiency determined from field measurements is larger than the efficiency determined using the windtable (Table 1) because of these differences.

Acknowledgments. The authors thank the following people for their contributions and assistance in the acquisition of equipment: Vickie L. Nadolski in the National Weather Service (NWS), Tom Blackburn in the NWS, and Karl Blauvelt in the School of Natural Resource Science, University of Nebraska. We are thankful for the valuable reviews by Dr. Albert Weiss and Dr. Kenneth F. Dewey of this manuscript. The original version of this manuscript greatly benefitted from insightful reviews by three anonymous reviewers.
REFERENCES

Albright, L. D., 1990: Environment Control for Animals and Plants. The American Society of Agricultural Engineers, $453 \mathrm{pp}$.

Brock, F. V., S. R. Semmer, and C. Jirak, 1995: Passive solar radiation shields: Wind tunnel testing. Preprints, Ninth Symp. on Meteorological Observations and Instrumentation, Charlotte, NC, Amer. Meteor. Soc., 329-334.

Bruun, H. H., 1995: Hot-Wire Anemometry, Principles and Signal Analysis. Oxford University Press, 507 pp.

Busch, N. E., and L. Kristensen, 1976: Cup anemometer overspeeding. J. Appl. Meteor., 15, 1328-1332.

Fritschen, L. J., and L. W. Gay, 1979: Environmental Instrumentation. Springer-Verlag, $216 \mathrm{pp}$.

Global Energy Concepts, Inc., 1999: Nebraska wind energy site data study. Final report, 58 pp. [Available from Nebraska Power Association, 444 S. 16th St. Mall, 4E/EP1, Omaha, NE 68102.]

Izumi, Y., and M. L. Barad, 1970: Wind speeds as measured by cup and sonic anemometers and influenced by tower structure. $J$. Appl. Meteor., 9, 851-856.

Lin, X., 1999: Microclimate inside air temperature radiation shields. $\mathrm{Ph} . \mathrm{D}$. thesis, University of Nebraska, $187 \mathrm{pp}$.

Perry, A. E., 1982: Hot-Wire Anemometry. Oxford University Press, $184 \mathrm{pp}$.

Richardson, S. J., 1995a: Passive solar radiation shields: Numerical simulation of flow dynamics. Preprints, Ninth Symp. on Meteorological Observations and Instrumentation, Charlotte, NC, Amer. Meteor. Soc., 253-258.

, 1995b: Multiplate radiation shields: Investigating radiational heating errors. Ph.D. thesis, University of Oklahoma, 133 pp. [Available online at http://www.oclc.org/firstsearch.]

Scheiman, J., C. Marple, and D. S. Vann, 1982: A calibration technique for a hot-wire-probe vector anemometer. NASA Tech. Memo. 83254, 48 pp.

TSI Inc., 1995: Model 8455/8465/8475 air velocity transducer. Service manual, $27 \mathrm{pp}$.

White, F. M., 1991: Viscous Fluid Flow. 2d ed. McGraw-Hill Series in Mechanical Engineering, McGraw-Hill, 614 pp.

WMO, 1983: Guide to meteorological instruments and methods of observation. WMO-8, 6th ed., WMO, Geneva, Switzerland, 248 pp.

Wyngaard, J. C., 1981: Cup, propeller, vane, and sonic anemometers in turbulence research. Аnnu. Rev. Fluid Mech., 13, 399-423. 